\title{
Mediating Organizational Cynicism: Exploring the Role of Hope Theory on Job Satisfaction
}

\author{
Franklin T. Kudo ${ }^{1}$, Keith H. Sakuda ${ }^{1, *}$, Garyn K. Tsuru ${ }^{2}$ \\ ${ }^{1}$ Division of Business Administration, University of Hawaii West Oahu, United States \\ ${ }^{2}$ Department of Student Affairs, University of Hawaii West Oahu, United States
}

Copyright $\bigcirc 2016$ by authors, all rights reserved. Authors agree that this article remains permanently open access under the terms of the Creative Commons Attribution License 4.0 International License

\begin{abstract}
The majority of research on groups and organizations has focused on the negative consequences of organizational life, but few studies have focused on how positive traits and qualities, such as hope, may impact groups. In this study we examined the relationship between hope, organizational cynicism and global job performance. All full-time employees $(n=95)$ of an educational institution were surveyed using existing scales for organizational cynicism $($ alpha $=0.94)$, hope $($ alpha $=0.87)$, and global job satisfaction (alpha $=0.87$ ). Hierarchical regression confirmed existing research and suggested a negative relationship between organizational cynicism and job satisfaction $(\mathrm{p}<0.001)$, and also provided evidence of a positive relationship between hope and job satisfaction $(\mathrm{p}<$ 0.05). Follow-up analysis showed hope partially mediated the negative relationship between organizational cynicism and global job satisfaction $(\mathrm{p}<0.01)$. This study contributes to the existing literature by discovering a positive relationship between hope and job satisfaction, as well as evidence of partial mediation in regards to organizational cynicism. Hope, which has been characterized as both a state of mind and a personal trait, appears to counter the negative effects of organizational cynicism. This suggests hope may allow individuals a means to address negative workplace attitudes and conditions.
\end{abstract}

Keywords Cynicism, Organizational Cynicism, Hope, Hope Theory, Job Satisfaction, Positive Organizational Behavior, Positive Psychology

\section{Introduction}

Cynicism has been proclaimed the modern day plague of the contemporary workplace. The popular media has described it as "rampant" [1], a "near epidemic" [2], and a "cancer" [3]; and has labeled it as a root cause of negative workplace issues such as lack of trust, blame, criticism, divisiveness, pessimism, sarcasm, and unengaged employees [4].

Cynicism and its negative effect on the workplace is not a new phenomenon. Organizational researchers have long examined cynicism as part of the modern employee-employer relationship [5,6]. Cynical employees were seen as those who were alienated because of their lack of virtues, ethics, and moralities which strayed from the ideals of their place of employment and the leaders of their organization [7].

Empirical research on cynicism in the workplace has found it to be both a consequence of various negative workplace experiences and an antecedent to numerous negative attitudinal and behavioral outcomes [8]. However, cynicism has also been associated with positive organizational outcomes. Just as the cynics of Greek society sought to reject the trappings and temptations of wealth, power, and social position in pursuit of truth; workplace cynics often play the role of the "voice of conscience" [9] or "devil's advocates" [10] to serve as a symbol of hope against wrongdoing in organizations.

Challenging one's organization and leader exposes one to reprisals, and cynical employees have been found to be burdened by higher levels of emotional exhaustion and lower levels of job satisfaction [11]. Despite these negative personal consequences, the cynics appear to remain steadfast in their hopeful determination or faith that improvements are possible. Otherwise, workplace exit or neglect would replace their attempts to voice dissatisfaction amid professional consequences. By clinging to some measure of hope, the cynic remains committed to their organization.

In this study we investigated trait hope as a possible mediator against the negativity typically associated with cynicism in the workplace. Following Snyder's[12] characterization of hope as an agency-pathway model, we propose that trait hope may help to mitigate the more deleterious effects of cynicism, and act as a deterrent against the negative thoughts and emotions that could damage the general well-being of the workplace. 


\section{Theory and Hypotheses}

\section{Organizational Cynicism and Job Satisfaction}

Anderson[7] defined cynicism towards business organizations and leaders as originating from the predominance of self-interested leaders, the assumption that organizational processes were driven by these self-interested individuals, and an acceptance that these processes were unlikely to change. Dean [9] and colleagues later conceptualized organizational cynicism as an attitude that combined a belief that the organization lacked integrity, a feeling of negative affect towards the organization, and critical or disparaging employee behaviors directed towards the organization. Unlike trait cynicism [13] or the social axiom of societal cynicism [14], organizational cynicism only encompassed the cynical attitudes towards the employing organization.

Research has found that the onset of cynicism towards an organization can be triggered by indirect experiences, such as observing the struggles of coworkers [15] or even viewing propaganda [16]. More commonly, organizational cynicism has been explained as being the result of perceived mistreatment or unfulfilled expectations about the employing organization [17-19]. Miscommunication and managerial hypocrisy regarding organizational values or ethics have also been shown to generate cynicism among employees [20].

Following the conceptualization proposed by Dean[9] and colleagues, organizational cynicism is often separated into the components of cognition (thinking), affect (feeling), and behavior (actions). As a cognitive belief, organizational cynicism is grounded in the perceptions one holds about their organization. These individual-based thoughts can be based on past events as well as future expectations in regards to the relationship between employee-employer [19,21]. As a result, one's mindset, as well as one's personality traits regarding interpretations of the past and anticipation of the future, can factor in determining the onset and consequences of organizational cynicism.

In regards to the affective component, organizational cynicism has a negative relationship with work attitudes such as job satisfaction and organizational commitment $[11,19,20,22,23,24]$. It has been argued that through the affect infusion model, thoughts of alienation towards the organization may diminish the overall job experience [25]. A meta-analysis by Chiaburu[8] and colleagues found a negative relationship with job satisfaction as the consequence of organizational cynicism with the largest effect size $(k=10)$. Organizational cynicism has also been linked to lower levels of perceived organizational support and justice [26,27], which are strong predictors of job satisfaction.

Cynical thoughts and attitudes in the relationship between employee and employer often manifest as negative behavioral outcomes. Research has uncovered an increase in undesirable employee actions such as frequent badmouthing of the organization [21] and employee deviance [23] from cynical employees. However, no definitive evidence has been found to link organizational cynicism to work performance behaviors [11,24]. A meta-analysis by Chiaburu [8] and colleagues suggested that cynicism impairs productivity, but the small number of analyzed studies that included job performance $(k=4)$ limited the effect size. While the onset of organizational cynicism does encourage behavioral changes, those behaviors are limited to expressions of dissatisfaction with work and the employer.

Hypothesis 1: Organizational cynicism will be negatively related to job satisfaction.

\section{Hope Theory and Job Satisfaction}

Hope theory, which originated from the field of clinical and counseling psychology, is a path-dependent process which focuses on inspiring success rather than focusing on failure [12]. It has been defined as the cognitive assessment of agency and pathways to successfully achieve goals [28]. Agency involves the thought processes that inspire an individual, and helps to direct more energy towards achieving one's goal. It provides motivation, and helps to sustain energy until the goal is accomplished. Pathways consist of the ability to produce different means and methods to achieve a goal. It is essential since being flexible, and able to change one's course of action is the key to success. The more pathways one is able to derive, the more resilient one is against failure.

The two components of agency and pathway separate hope theory from the more commonly used definition of hope as feeling something positive will happen or having faith towards a positive outcome. Both hope theory and common hope require a positive disposition state, but hope theory also requires the trait to take action and be responsible for proper planning and determination amid setbacks or failures.

Early organizational researchers recognized the potential value hope could offer to their field of study by inspiring a future focused on a moral image of social and organizational life. Ludema[29] and colleagues identified hope as being grounded in social relationships, based in appreciative approaches, pragmatic in its transformative power, and transcendent beyond individual interests. Despite those aspirational intentions, there has been a dearth in empirical research conducted on hope.

Organizational research in hope received a boost from the Positive Psychology movement. It calls for researchers to build upon the strengths and qualities of an individual, and has led to a new focus on the more positive aspects of life and organizations. Building upon the Positive Psychology movement, the field of Positive Organizational Behavior (POB) focuses on applying positive behaviors towards work. Essential to the core of POB were the embedded capacities of self-efficacy and resiliency [30] and a special emphasis on hope [31,32].

Empirical research on hope is limited, but hope has been found to have a positive relationship with job performance $[30,31,33,34]$ and organizational commitment $[35,36]$. It is 
believed that the cognitive processes and behaviors associated with higher levels of hope lead people to develop multiple pathways to achieve their desired goals. More importantly, by encouraging different thought processes and behaviors, the hopeful individual is better able to reframe adversity and push past disappointment in the workplace [34].

To date there has been no empirical research on a possible relationship between hope theory and job satisfaction. As an indicator of an employees' attitude towards their jobs and different aspects of their jobs [37], job satisfaction has been found to be related to both individual and organizational values [38,39]. Higher levels of job satisfaction have been linked to higher levels of job performance [40], organizational commitment [41], organizational citizenship behaviors [42], and loyalty to the organization [43]. Lower levels of job satisfaction have been found to be related to higher levels of organizational deviance, such as absenteeism [44], tardiness [45], and employee turnover [46].

Although the agency-pathway model of hope theory provides little theoretical basis for a relationship with job satisfaction, the demonstrated ability of hopeful individuals to push through adversity and disappointment is suggestive of a cognitive ability not found in those with lower levels of hope. Whether it is through higher levels of motivation, proactivity, or resiliency, hopeful individuals appear more capable of persevering through difficulties to find satisfaction in the workplace. Trait hope is also strongly associated, though distinct from positive constructs such as optimism and self-efficacy [28], to job satisfaction.

Hypothesis 2: Trait hope will be positively related to job satisfaction.

\section{Methods}

\section{Sample}

Permission to conduct the study was granted by the University's Institutional Review Board and administration. Participants in the study were 95 full-time faculty and staff from an educational institution. All surveys were distributed and collected in-person during work hours. To encourage cooperation, all participants were compensated with a gift card to a local business. Anonymity was assured as all completed surveys were submitted in a sealed container, and the handling of completed surveys and data entry was completed by independent third-parties not affiliated with the institution. Several surveys were discarded due to missing data, leaving a final sample size of 86 observations.

\section{Measures}

Organizational cynicism was operationalized using a five-point, fourteen-item scale developed by Dean [9] and colleagues. This previously established scale is one of the few measures of organizational cynicism that has published and released all items to the public [8]. The survey asks respondents to indicate their thoughts, feelings, and behaviors specific to their jobs. Higher scores indicate higher levels of organizational cynicism. For this sample, the Cronbach's alpha was 0.94 .

Hope was measured using Snyder's Hope Scale [12]. This eight-item scale was originally designed to help professional counselors understand the change process in clients [28], but it has gained acceptance as a standard for measuring hope in organizational research $[34,35]$. The survey asks respondents to indicate their thoughts regarding their ability to direct their energy and focus towards planning and meeting goals [47]. The Cronbach's alpha for hope was 0.87 .

Global job satisfaction was measured using the Michigan Organizational Assessment Questionnaire Job Satisfaction Subscale [48]. The five-point, three-item scale provides a condensed assessment of the three dimensions of job satisfaction. The Cronbach's alpha for global job satisfaction was 0.87 .

\section{Control variables}

Age, Gender ("female," 0; "male," 1), and Semesters (proxy variable for workplace tenure) were selected as demographic control variables. Although a meta-analysis by Chiaburu[8] and colleagues found no significant relationship between age, gender, or workplace tenure with organizational cynicism, it should be noted that virtually all quantitative studies on organizational cynicism included those three control variables.

Hierarchical regression modeling was conducted to test the hypotheses. In the first block the control variables of age, gender, and semesters were regressed against global job satisfaction. Organizational cynicism was added to the model in the second block to test H1, and hope was added to the final block to test H2. Descriptive statistics and intercorrelations are shown in Table 1.

Table 1. Intercorrelations and descriptive statistics

\begin{tabular}{|c|c|c|c|c|c|c|c|c|}
\hline Variable & $\mathrm{M}$ & $\mathrm{STD}$ & Job Satisfaction & Age & Gender & Semesters & $\begin{array}{c}\text { Organizational } \\
\text { Cynicism }\end{array}$ & Hope \\
\hline Job Satisfaction & 12.58 & 2.13 & 1.00 & -- & -- & -- & -- & -- \\
\hline Age & 42.45 & 11.82 & -0.16 & 1.00 & -- & -- & -- \\
\hline Gender & -- & -- & 0.00 & 0.016 & 1.00 & -- & -- & -- \\
\hline Semesters & 8.72 & 8.45 & $-0.33^{* *}$ & $0.36^{* *}$ & 0.14 & 1.00 & -- & -- \\
\hline $\begin{array}{c}\text { Organizational } \\
\text { Cynicism }\end{array}$ & 36.09 & 12.10 & $-0.71^{* *}$ & 0.12 & 0.04 & $0.45^{* *}$ & - & 1.00 \\
\hline Hope & 55.31 & 5.97 & $0.41^{* *}$ & 0.05 & 0.05 & -0.17 & $-0.33^{* *}$ & 1.00 \\
\hline
\end{tabular}

\footnotetext{
${ }^{*} p<0.05 .{ }^{* *} p<0.01 .{ }^{* * *} p<0.001$.
} 
Table 2. Regression model results

\begin{tabular}{|c|c|c|c|}
\hline Variable & Model 1 & Model 2 & Model 3 \\
\hline Intercept & 13.323 & 17.476 & -330 \\
\hline Control Variables & & & -0.016 \\
\hline AGE & -0.008 & -0.015 & 0.070 \\
\hline GENDER & 0.198 & 0.123 & 0.070 \\
\hline SEMESTERS & $-0.080^{* *}$ & 0.004 & $-0.113^{* * *}$ \\
\hline Organizational Cynicism & -- & $-0.124^{* * *}$ & $0.070^{*}$ \\
\hline Hope & -- & -- & $0.51^{*}$ \\
\hline
\end{tabular}

${ }^{*} p<0.05 .{ }^{* *} p<0.01 .{ }^{* * *} p<0.001$.

\section{Results}

Table 2 reports the results from the hierarchical regression analysis. Model 1 indicates that the control variable semesters $(p<0.01)$ was significant with respect to global job satisfaction, but age and gender were not significant. The aggregated control variables accounted for $7.9 \%(\mathrm{p}<0.05)$ of the variance in global job satisfaction.

Organizational cynicism was added to the hierarchical regression analysis in the second block of variables. With the addition of organizational cynicism, all three control variables showed no significance to job satisfaction. Organizational cynicism had a negative significant relationship to job satisfaction $(\mathrm{p}<0.001)$, providing strong support for H1. The finding is consistent with previous findings that organizational cynicism is negatively related to job satisfaction [8]. The adjusted r-squared of the model increased to $0.48(\mathrm{p}<0.001)$.

Hope was added to the model in the final block of variables. All control variables from the previous block remained insignificant, and the negative relationship between organizational cynicism and job satisfaction remained significant $(p<0.01)$. Hope had a positive significant relationship to job satisfaction, providing strong support for $\mathrm{H} 2(\mathrm{p}<0.05)$. The adjusted $\mathrm{r}$-squared of the model increased slightly to $0.51(\mathrm{p}<0.05)$. The Sobel test revealed a significant indirect effect of partial mediation ( $p$ $<0.01)$.

\section{Discussion}

In addition to confirming previously established findings for organizational cynicism, this study contributes to research by discovering a positive relationship between hope and job satisfaction. Hope, which has been characterized as both a state of mind and a trait, appears to work counter to the more commonly studied phenomenon of cynicism. Hopeful individuals also seem well suited to address the negative thoughts, feelings, and behaviors associated with organizational cynicism. Mistrust in their organization or its leadership may discourage the less hopeful, but hopeful individuals would be better able to maintain their energy and focus while developing pathways to work around perceived obstructions in their organization.

The lack of organizational research related to hope and other positive psychology constructs is symptomatic of the mindset that understanding what is "wrong" in the workplace takes precedent over understanding what is "right" in the workplace. As research moves away from a focus on negative organizational maladies like cynicism, it is likely that new positive constructs will be revealed which promote greater human potential and productivity. Just as Herzberg's[49] two-factor theory championed motivators over hygiene factors, positive concepts such as hope may provide a mechanism to motivate and inspire in the workplace.

The findings also have several workplace implications. Cynicism has long dominated the mindset of the modern workplace. As noted in this study and others, cynicism evokes a negative emotional spiral that leads to a poorer emotional state for workers. Organizational researchers and the popular business media have offered various solutions to cynicism such as improved work communication, employee empowerment, and information sharing, but are all dependent on management for implementation. While such remedies are likely to reduce cynicism, it is unlikely that a truly self-interested organization would seek to implement such initiatives. More importantly, it is unlikely that employees who possess the three traits of organizational cynicism: belief that their company lacks integrity, negative feelings towards the company, and disparaging employee behavior, would be willing to participate in such initiatives.

In contrast, hope, being an individual-based trait, begins with the individual. Those who aspire to improve their work life can initiate their own programs independent of their organization to instill a greater level of hope into their mindset. Theory clearly states that hope is a cognitive state of mind dependent on path and agency towards a goal. While it may be easier to develop path and agency at trusted and supportive organizations, proper goal-setting and creativity may empower individuals to develop hope regardless of their workplace environments. Workshops on both goal-setting strategies and fostering creativity, whether through 
professional development seminars, self-help books, or life coaching sessions, are widely available.

Managers who seek to improve job satisfaction in their organizations may also benefit from this study. As mentioned above, improved work communication, employee empowerment, and information sharing have long been argued to reduce cynicism, but now a focus on goal-setting, agency, and pathways can be added to those initiatives to improve hope. Focusing communication to emphasize the specific information employees need to accomplish their goals, as well as highlighting how such information can be used, will create much clearer pathways towards success, while empowerment programs focusing on goal-oriented behaviors will improve goal-setting and agency. By providing the components of the theory, managers can foster an environment that encourages hope among employees.

\section{Limitations and Future Research}

This study has several limitations. The research design and methodology primarily investigates the relationship between hope and job satisfaction, even though there is the possibility that hope may work as a moderator or mediator in regards to the relationship between organizational cynicism and job satisfaction. Whether as a personality trait or a state of mind, hope is likely to exist with a degree of independence from work life. If so, it would be valuable for future research to explore the relationship between cynicism and hope.

Some criticism may be directed towards the small effect size of the findings. Including hope into the regression model only explained an additional 3 percent of variance. However, it should be noted that Snyder's Hope Theory, from which the scale used in this study originated, was originally designed for psychological counseling. Future research may seek to develop a more optimal measure for dealing with hope within the context of organizational and work research. Despite the small effect size observed in this study, the potential benefits to employee well-being from adding hope to the organizational research agenda makes it a worthy topic to pursue.

Perhaps the greatest limitation of the study is the sample. Although a tremendous effort was made to survey all full-time employees of the university, only 86 observations were usable in the final analysis. Future work should seek a larger sample, perhaps by including part-time employees. It is also possible the findings may be attributed to the specific nature of the university used in the study. Restricting the sample to a single institution provided convenience and offered a common work experience for all participants in the study. However, the common work experience may potentially limit the generalizability of the findings to other organizations.

Although the study has its limitations, it does provide impetus for future organizational research into hope. The modern workplace seems to be growing more and more cynical, leaving employees awash in a wave of negativity.
Positive psychology traits, such as hope, may serve as a needed counterbalance to reframe employee-employer relations to reinvigorate human potential and happiness at work.

\section{REFERENCES}

[1] B. Dattner, D. Dahl. The Blame Game: How the Hidden Rules of Credit and Blame Determine Our Success of Failure. Free Press, New York USA, 2012.

[2] M. Pearson. Workplace Shaman: Dispelling workplace cynicism, Online available from http://business.financialpost.com/executive/careers/workplac e-shaman-dispelling-workplace-cynicism

[3] L. Arussy. Rooting out the "cancer" of employee cynicism. Online available from

http://www.hrzone.com/engage/customers/rooting-out-the-ca ncer-of-employee-cynicism

[4] J. Showkeir, M. Showkeir. Cynicism - The price we all pay. Online available from http://intentionalworkplace.com/2010/09/01/cynicism-\%E2 $\% 80 \% 93$-the-price-we-all-pay

[5] D. L. Kanter, P.H. Mirvis. The cynical Americas. Jossey-Bass, San Francisco USA, 1989.

[6] P. H. Mirvis, D. L. Kanter. Beyond demography: A psychographic profile of the workforce. Human Resource Management, 30(1), 45-68, 1991

[7] L. M. Andersson. Employee cynicism: An examination using a contract violation framework. Human Relations, 49(11), 1395-1418, 1996.

[8] D. S. Chiaburu, A. C. Peng, I. S. Oh, G. C. Banks, L.C. Lomeli, Antecedents and consequences of employee organizational cynicism: A meta-analysis. Journal of Vocational Behavior, 83(2), 181-197, 2013.

[9] J. W. Dean, P. Brandes, R, Dharwadkar, R. Organizational cynicism. Academy of Management Review. 23(2), 341-352, 1998.

[10] P. Brandes, D. Das. Locating behavioral cynicism at work: Construct issues and performance implications. Research in Occupational Stress and Well-being, 5, 233-266, 2006.

[11] J. L. Johnson, A. M. O'Leary-Kelly, A. M. The effects of psychological contract breach and organizational cynicism: Not all social exchange violations are created equal. Journal of Organizational Behavior, 24(5), 627-647, 2003.

[12] C. R. Snyder, C. Harris, J.R. Anderson, S. A. Holleran, L. M. Irving, S. T. Sigmon, L. Yoshinobu, J. Gibb, C. Langelle, P. Harney. The will and the ways: Developing and validation of an individual-differences measure of hope. Journal of Personality and Social Psychology, 60(4), 570-585, 1991.

[13] L. S. Wrightsman. Assumptions about human nature: A social psychological analysis. Brooks/Cole, Monterey, USA, 1974.

[14] K. Leung, M. H. Bond, S. R. DeCarrasquel, C. Munoz, M. Hernandez, F. Murakami, S. Yamaguchi, G. Bierbrauer, T. M. 
Singelis. Social axioms: The search for universal dimensions off general beliefs about how the world functions. Journal of Cross-Cultural Psychology, 33(3), 286-302, 2002.

[15] A. K. Mishra, G. M. Preitzer. Explaining how survivors respond to downsizing: The roles of trust, empowerment, justice, and work redesign. Academy of Management Review, 23(3), 1998.

[16] T. S. Bateman, T. Sakano, M. Fujita. Roger, me, and my attitude: Film propaganda and cynicism toward corporate leadership. Journal of Applied Psychology, 77(5), 768-771, 1992.

[17] L. M. Andersson, T. S. Bateman. Cynicism in the workplace: Some causes and effects. Journal of Organizational Behavior, 18(5), 449-469, 1997.

[18] M. S. Cole, H. Brunch, B. Vogel. Emotion as mediators of the relations between perceived supervisor support and psychological hardiness on employee cynicism. Journal of Organizational Behavior, 27(4), 463-484, 2006.

[19] A. E. Reichers, J. P. Wanous, J. T. Austin (1997). Understanding and managing cynicism about organizational change. Academy of Management Executive, 11(1), 48-59, 1997.

[20] J. H. Fritz, N.B. O’Neil, A.M. Poop, C. Williams, R. C. Arnett. The influence of supervisory behavioral integrity on intent to comply with organizational ethical standards and organizational commitment. Journal of Business Ethics, 114, 251-263, 2013.

[21] J. M. Wilkerson, W.R. Evans, W. D. Davis. A test of coworkers' influence on organizational cynicism, badmouthing, and organizational citizenship behavior. Journal of Applied Social Psychology, 38(9), 2273-2292, 2008.

[22] R. Abraham. Organizational cynicism: Bases and consequences. Genetic, Social, and General Psychology Monographs, 126(3), 269-292, 2000

[23] W. R. Evans, J. M. Goodman, W. D. Davis. The impact of perceived corporate citizenship on organizational cynicism, OCB, and employee deviance. Human Performance, 24(1), 79-97, 2011.

[24] P. Neves. Organizational cynicism: Spillover effects on supervisor-subordinate relationships and performance. The Leadership Quarterly, 23(5), 965-976, 2012.

[25] J. P. Forgas. Mood and judgement: The affect infusion model (AIM). Psychological Bulletin, 117, 39-66, 1995.

[26] J. A. Colquitt, D. E. Conlon, M. J. Wesson, C. O. L. H. Porter, K. Y. Ng. Justice in the millennium: A meta-analytic review of 25 years of organizational justice research. Journal of Applied Psychology, 86, 425-455, 2001.

[27] R. J. Riggle, D. R. Edmondson, J. D. Hansen. A meta-analysis of the relationship between perceived organizational support and job outcomes: $20 \mathrm{y}$ ears of research. Journal of Business Research, 62(10), 1027-1030, 2009.

[28] C. R. Snyder. Conceptualizing, measuring, and nurturing hope. Journal of Counseling and Development, 73(3), 355-360, 1995.

[29] J. D. Ludema, T. B. Wilmot, S. Srivastva. Organizational hope:
Reaffirming the constructive task of social and organizational inquiry. Human Relations, 50(8), 1015-1052, 1997.

[30] F. Luthans. The need for and meaning of positive organizational behavior. Journal of Organizational Behavior, 23(6), 695-706, 2002.

[31] F, Luthans. Positive organizational behavior: Developing and managing psychological strengths. Academy of Management Executive, 16(1), 57-72, 2002.

[32] C. M. Youssef, F. Luthans. Positive organizational behavior in the workplace: The impact of hope, optimism, and resilience. Journal of Management, 33(5), 774-800, 2007.

[33] M. H. Jafri. A study of the relationship of psychological capital and students' performance. Business Perspectives and Research, 1(2), 9-16, 2013.

[34] S. J. Peterson, K. Byron. Exploring the role of hope in job performance: Results from four studies. Journal of Organizational Behavior, 29(6), 785-803, 2008.

[35] D. Ozag. The relationship between the trust, hope, and normative and continuance commitment of merger survivors. Journal of Management Development, 25(9), 870-883, 2006.

[36] P. E. Spector. Job satisfaction application, assessment, cause, ad consequences, Sage Publications, Thousand Oaks, USA, 1997.

[37] D. Diskiene, V. Gostautas. Relationship between individual and organizational values and employees job satisfaction. Current Issues of Business \& Law, 5(2), 295-319, 2010.

[38] D. Diskiene, V. Gostautas. A fit between individual and organizational values and its implications for employees' job satisfaction and performance. Economika, 92(2), 93-107, 2013.

[39] M. M. Gruneberg. Understanding job satisfaction. John Wiley, New York, USA, 1979.

[40] R. P. Mowday, R. M. Steers, L.W. Porter. The measurement of organizational commitment. Journal of Vocational Behavior, 14, 234-247, 1979

[41] C. L. Hulin, T. A. Judge. Job attitudes. In W.C. Borman, D. R. Ilgen, D. R. Klimoski, \& R.J. Hoboken (Eds.), Handbook of industrial and organizational psychology, 255-276. John Wiley, New York USA, 2003.

[42] J. J. Trombetta, D. P. Rogers. Communication climate, job satisfaction, and organizational commitment: The effects of information adequacy, communication openness, and decision participation. Management Communication Quarterly, 1, 494-514, 1998.

[43] A. Sagie. Employee absenteeism, organizational commitment, and job satisfaction: Another look. Journal of Vocational Behavior, 52, 156-171, 1998.

[44] R. D. Iverson, S. J. Deery. Understanding the "personological" basis of employee withdrawal: The influence of affect disposition on employee tardiness, early departure, and absenteeism. Journal of Applied Psychology, 86, 856-866, 2001.

[45] G. Johns. The psychology of lateness, absenteeism, and turnover. In N. Anderson, D.S. Ones, H. K. Singangil, \& C. Viswesvaran (Eds.), Handbook of industrial, work and organizational psychology, 232-252, Sage, Thousand Oaks, 
USA, 2002.

[46] M. A. Babyak, C. R. Snyder, L. Yoshinobu. Psychometric properties of the Hope Scale: A confirmatory factor analysis. Journal of Research in Personality, 27, 154-169, 1993.

[47] N. A. Bowling, G. D. Hammond. A meta-analytic examination of the construct validity of the Michigan Organizational Assessment Questionnaire Job Satisfaction Subscale. Journal of Vocational Behavior, 73(1) 63-77, 2008

[48] F. Herzberg. The motivation-hygiene concept and problems of manpower. Personnel Administrator, 27, 3-7, 1964. 